\title{
TO STUDY THE PREVALENCE OF PRE-CANCEROUS CONDITIONS OF CERVIX- A HOSPITAL-BASED STUDY
}

\author{
H. K. Cheema ${ }^{1}$, Kulbir Kaur², Harshdeep Joshi ${ }^{3}$
}

${ }^{1}$ Associate Professor, Department of Obstetrics and Gynaecology, Punjab Institute of Medical Sciences, Jalandhar, Punjab.

2Professor, Department of Pathology, Punjab Institute of Medical Sciences, Jalandhar, Punjab.

${ }^{3}$ Assistant Professor, Department of Community Medicine, Punjab Institute of Medical Sciences, Jalandhar, Punjab.

\begin{abstract}
BACKGROUND
ABSTRACT

Carcinoma of the cervix is the $3^{\text {rd }}$ most common carcinoma of women. It is a leading cause of morbidity and mortality in India. About $86 \%$ of cases occur in developing countries and $88 \%$ deaths occur due to cervical carcinoma in developing countries. Pap smear is a simple, non-invasive, cost-effective tool in every Gynaecological OPD which can detect abnormal cytological findings of cervix. It can detect pre-cancerous lesions of the cervix at the earliest and effective early treatment can save women from morbidity and mortality.

Aims and objectives of the study were to determine the prevalence of pre-cancerous conditions of the cervix in a hospital-based population in Punjab Institute of Medical Sciences, Garha Road, Jalandhar, Punjab.
\end{abstract}

\section{MATERIALS AND METHODS}

A hospital-based cross-sectional study was conducted. This was questionnaire-based study. Questionnaire was administered to 500 women attending Gynaecological OPD. The questionnaire consisted of the questions regarding the knowledge and awareness about different aspects of cervical cancer. All relevant socio-demographic parameters, detailed history, clinical examination, per speculum examination and Pap smear cytological study were done. This study was approved by Institutional Ethical Committee. 500 women coming to Gynae OPD with chronic discharge P/V, post-coital bleeding, post-menopausal bleeding P/V, other menstrual abnormalities, lower abdominal pain and routine Pap smear screening between age group 18 (or age of 1 st coituswhichever was low) till 65 years of age were included in the study. The data collected during the survey was entered in Microsoft Excel and analysed via SPSS (Statistical Package for the Social Sciences) SPSS version 20.

\section{RESULTS}

Out of 500 cases studied, 458 cases (91.6\%) were satisfactory according to Bethesda System. The epithelial cell abnormalities constituted 42 (8.4\%). Maximum no. of cases 210 (42\%) were in the age group $>40$ years. Co-relation of early marriage/ $1^{\text {st }}$ coitus and increasing age with abnormal cytological findings was statistically significant ( $\mathrm{p}$ value- 0.001) along with cervical morbidity on per speculum findings. The statistically significant co-relation was found ( $p$ value- 0.001 ) between multiparity (40.7\%) and abnormal cervical smear findings. ASCUS was (5.4\%) followed by LSIL (1.4\%), HSIL (0.8\%) and SCC (0.8\%).

\section{CONCLUSION}

The study clearly shows relatively high prevalence of epithelial abnormalities in cervical Pap smear with increasing age, parity and early age at first coitus in symptomatic women with clinical lesions on per speculum findings. Effective screening with Pap smear definitely helps in early detection of precancerous lesions of cervix. Effective, frequent Pap smear screening programmes should be organised in India, even in the remotest rural areas to prevent the incidence of invasive cervical carcinoma.

\section{KEYWORDS}

Pap Smear Screening, Cervical Cancer, Cytology.

HOW TO CITE THIS ARTICLE: Cheema HK, Kaur K, Joshi H. To study the prevalence of pre-cancerous conditions of cervix- a hospital-based study. J. Evolution Med. Dent. Sci. 2018;7(05):615-618, DOI: 10.14260/jemds/2018/139

\section{BACKGROUND}

Carcinoma of the cervix is one of the most common carcinomas among women worldwide,(1) most frequent carcinoma in women in India.(2) It is also the most common cancer in women in many parts of the world including southcentral Asia.(1) It has been the most important carcinoma in women in India constituting $11 \%-30 \%$ of all cancers in women

'Financial or Other Competing Interest': None.

Submission 11-07-2017, Peer Review 14-01-2018,

Acceptance 20-01-2018, Published 29-01-2018.

Corresponding Author:

Dr. Kulbir Kaur,

Professor, Department of Pathology,

PIMS, Jalandhar.

E-mail:drkulbirkaur@yahoo.co.in principal.pims@pimsj.com drhkcheema@gmail.com

DOI: $10.14260 /$ jemds $/ 2018 / 139$ and has become the leading cause of mortality and morbidity.(3) About $86 \%$ of cases occur in developing countries and about $88 \%$ deaths occur due to cervical cancer in developing countries.(4) Risk factors include persistent infection with high-risk strains of Human Papilloma virus, other risk factors include early age at marriage, multiparity, less spacing between pregnancies, low socio-economic status, prolonged use of oral contraceptives and smoking.(5)

Women in developing countries usually present to the clinic only when they have symptoms such as pain, discharge $\mathrm{P} / \mathrm{V}$ and abnormal bleeding P/V.(6) The risk of cervical cancer remains high in many developing countries, usually due to lack or inefficiency of existing preventive programmes. To detect abnormal precancerous cells in cervix, before patients get any symptoms, a very simple, non-invasive, cost-effective test for mass screening is used named as "Papanicolaou (Pap) smear test. It is used for the diagnosis of cervical precancerous and cancerous lesions.(7) 
Screening of women coming to routine Gynaecological OPD with symptoms of pain, vaginal discharge, abnormal bleeding if subjected to Pap smear screening, by Bethesda System 2001, will go a long way in terms of lives saved and cancer of cervix prevention. Early detection of epithelial abnormalities helps in early treatment of dysplastic epithelial changes (CIN1 to CIN III), can prevent invasive cervical carcinoma.

\section{Aims and Objectives}

1. To determine the prevalence of precancerous conditions of cervix (CIN I-III) in women with chronic vaginal discharge and sexually active women by screening with Pap smear in hospital-based population in Punjab Institute of Medical Sciences, Garha Road, Jalandhar.

2. To find out detection rate of epithelial abnormalities of cervix.

\section{MATERIALS AND METHODS}

The study was conducted in the Department of Obstetrics and Gynaecology in Punjab Institute of Medical Sciences, Jalandhar. This study has been approved by the Ethical Committee of the Institution. The study was a cross-sectional study, comprising of 500 women in age group of 18 (or age of $1^{\text {st }}$ coitus - whichever was low) - 65 years, coming to Gynaecological OPD, who were sexually active and with symptoms of chronic vaginal discharge or post-coital bleeding $\mathrm{P} / \mathrm{V}$ or intermenstrual bleeding $\mathrm{P} / \mathrm{V}$ or lower abdominal pain and women with no complaints, but for routine cancer screening. Purpose of the study was explained to the patients and informed written consent was taken. This was questionnaire-based study. Questionnaire was administered to 500 women attending Gynaecological OPD. The questionnaire consisted of the questions regarding the knowledge and awareness about different aspects of cervical cancer. Detailed findings including age, gravida/ para, space between children, prolonged use of oral contraceptives, smoking, age at marriage/ $1^{\text {st }}$ coitus, marital status, socioeconomic status, detailed clinical and menstrual history, postcoital bleeding, vaginal discharge and per speculum clinical examination were recorded on the pre-designed, prestructured proforma. After doing per speculum examination with Cusco's speculum, cervical scrape smears were collected using Ayer's spatula and endocervical brush. Cervical scrapings were spread on a glass slide and dipped in Ethanol solution container. Pap smears of all the patients were collected and sent to pathology department. The smears were stained using Papanicolaou method. The cytological abnormalities were classified according to The Bethesda System 2001 by the pathologist after examining Pap smears.

\section{Data Analysis}

Data was analysed using SPSS Version 20 (IBM, Chicago, USA). To find out the association between attributes, Chisquare test was applied and $p$ value of $<0.05$ was considered to be statistically significant.

\section{RESULTS}

500 women attending Gynaecology OPD in Punjab Institute of Medical Sciences, Jalandhar were subjected to cervical Pap smear during the study period. It was found that out of 500 cases studied, 458 cases (91.6\%) were satisfactory according to Bethesda System. The epithelial cell abnormalities constituted $42(8.4 \%)$ of all cases. Maximum no. of cases 210 $(42 \%)$ were in age group of more than 40 years followed by age 18 - 25 years 84 (16.8), 30 - 35 years 71 (14.2\%), 36 - 40 years $67(13.4 \%)$ and 26 - 30 years 58 (11.6\%). The Epithelial abnormalities included $8.4 \%$ of all cases, out of which ASCUS (atypical squamous cells of undetermined origin) was $5.4 \%$ followed by LSIL (low squamous intraepithelial lesion) $1.4 \%$ followed by HSIL (high squamous intra-epithelial lesion) $0.8 \%$ and SCC (squamous cell carcinoma) $0.8 \%$. Most common age group affected by ASCUS was $>40$ years of age. 2 patients showed SCC at age $31-35$ years. Out of 458 normal cases, 151 were detected with cervical erosion or cervicitis. There were 42 abnormal smears, out of which ASCUS (27) was the most common.

The frequency of dysplasia and cervical carcinoma in relation to age is shown in Table No. 1 . The progressive rise in epithelial abnormalities was seen with increasing age and maximum frequency was seen in age $>40$ years. Age at first coitus was calculated and it showed $86 \%$ women were of group (18 - 25) yrs., 9.2\% (< 18 yrs.), 3.8\% in (26 - 30) yrs. with just $1 \%$ in $>30$ yrs. Relationship of early marriage/ $1^{\text {st }}$ coitus with cervical morbidity showed clearly that it has significant influence ( $\mathrm{p}$ value $<0.001$ ) on cervical morbidity. Symptoms were maximum as discharge $\mathrm{P} / \mathrm{V}(30 \%)$, pain lower abdomen $(25.6 \%)$, pruritus vulva $(11.6 \%)$, post-coital bleeding (5.6\%), post-menopausal bleeding (5.2\%), menorrhagia $(4.6 \%)$, dyspareunia $(2.6 \%)$ and infertility (0.6\%). Maximum P/S findings were of cervical erosion/ cervicitis $(83.2 \%)$ in 18 - 25 age group followed by $<18$ yrs. $8.8 \%$. It showed that more the no. of yrs. of coitus, more the risk of cervical morbidity.

Relationship of parity with abnormal Pap smear was analysed and it was found that multipara ( 4 or $>4$ children) were having maximum cervical morbidity $(40.7 \%)$ followed by women with 3 children (18.75\%) and women with $1-2$ children $(11.8 \%)$. Parity is also proved to be statistically significant ( $\mathrm{p}$ value $<0.001$ ). In the study group as only 3 women were smokers, the association of smoking with dysplasia could not be predicted. All 500 women were classified according to Kuppuswamy classification into upper, middle and lower class. Prevalence of cervical dysplasia was higher in low socio-economic group, but it was not statistically significant.

\begin{tabular}{|c|c|c|}
\hline Age Group & No. & Percentage \\
\hline$<18$ & 10 & $2 \%$ \\
\hline $18-25$ & 84 & $16.8 \%$ \\
\hline $26-30$ & 58 & $11.6 \%$ \\
\hline $31-35$ & 71 & $14.2 \%$ \\
\hline $36-40$ & 67 & $13.4 \%$ \\
\hline$>40$ & 210 & $42 \%$ \\
\hline Age at Marriage & No. & Percentage \\
\hline$<18$ & 44 & $8.8 \%$ \\
\hline $18-25$ & 417 & $83.4 \%$ \\
\hline $26-30$ & 33 & $6.6 \%$ \\
\hline$>30$ & 6 & $1.2 \%$ \\
\hline Age at First Coitus & No. & Percentage \\
\hline$<18$ & 46 & $9.2 \%$ \\
\hline $18-25$ & 430 & $86 \%$ \\
\hline $26-30$ & 19 & $3.8 \%$ \\
\hline$>30$ & 5 & $1 \%$ \\
\hline Total & 500 & $100 \%$ \\
\hline
\end{tabular}


Table 1 depicts the socio-demographic profile of the participants. It is clearly evident from the above table that maximum number of study subjects belong to the age group of $>40$ years. Majority of the participants got married at the age of 18 - 25 years. Similarly, the age of first coitus is maximum in the same age group, i.e. 18 - 25 years.

\begin{tabular}{|c|c|c|}
\hline Symptom & No. & Percentage \\
\hline Discharge PV & 150 & $30 \%$ \\
\hline Pain lower abdomen & 128 & $25.6 \%$ \\
\hline Pruritus vulva & 58 & $11.6 \%$ \\
\hline Post-coital bleed & 18 & $3.6 \%$ \\
\hline $\begin{array}{c}\text { Discharge PV + pain lower abdomen } \\
\text { + post-coital bleed }\end{array}$ & 78 & $15.6 \%$ \\
\hline
\end{tabular}

\begin{tabular}{|c|c|c|}
\hline Menorrhagia & 23 & $4.6 \%$ \\
\hline Postmenopausal bleed & 26 & $5.2 \%$ \\
\hline Primary infertility & 3 & $0.6 \%$ \\
\hline Dyspareunia & 13 & $2.6 \%$ \\
\hline Something coming out from vagina & 2 & $0.4 \%$ \\
\hline Any other & 1 & $0.2 \%$ \\
\hline Total & $\mathbf{5 0 0}$ & \\
\hline Table 2. Type of Reproductive Tract Morbidity \\
\hline
\end{tabular}

Table 2 represents the type of reproductive tract morbidity among study subjects. Discharge per vaginum was the commonest complaint (30\%) followed by symptoms like pain lower abdomen (25.6\%)

\begin{tabular}{|c|c|c|c|c|c|c|}
\hline Age at Marriage & Normal & Erosion/ Cervicitis & Hypertrophy & Atrophy & Total & P value \\
\hline$<18$ & $29(17.4 \%)$ & $12(5.85 \%)$ & $2(2.27 \%)$ & $1(2.43 \%)$ & $44(8.8 \%)$ & \multirow{4}{*}{$\mathrm{p}<0.001$} \\
\hline $18-25$ & $123(74.09 \%)$ & $175(85.36 \%)$ & $82(93.18 \%)$ & $37(2.43 \%)$ & $417(83.2 \%)$ & \\
\hline $26-30$ & $12(7.22 \%)$ & $16(7.80 \%)$ & $3(3.04 \%)$ & $2(4.87 \%)$ & $33(6.6 \%)$ & \\
\hline$>30$ & $2(1.20 \%)$ & $2(0.97 \%)$ & $1(1.13 \%)$ & $1(2.43 \%)$ & $6(1.2 \%)$ & \\
\hline \multicolumn{7}{|c|}{ Parity } \\
\hline 0 & $9(37.5 \%)$ & $10(4.34 \%)$ & $50(30.86 \%)$ & $1(1.85 \%)$ & $70(14 \%)$ & \multirow{6}{*}{$\mathrm{P}<0.001$} \\
\hline 1 & $7(29.16 \%)$ & $10(4.34 \%)$ & $48(25 \%)$ & $2(3.7 \%)$ & $67(13.4 \%)$ & \\
\hline 2 & $4(16.6 \%)$ & $12(5.21 \%)$ & $40(20.83 \%)$ & $3(5.55 \%)$ & $59(11.8 \%)$ & \\
\hline 3 & $2(8.33 \%)$ & 47 (20.43\%) & $36(18.75 \%)$ & $9(16.65 \%)$ & $94(18.8 \%)$ & \\
\hline 4 & $1(4.16 \%)$ & $60(26.08 \%)$ & $10(6.17 \%)$ & $17(31.45 \%)$ & $88(37.6 \%)$ & \\
\hline$>4$ & $1(4.16 \%)$ & $91(39.56 \%)$ & $8(4.16 \%)$ & $22(40.7 \%) \mathrm{S}$ & $122(24.4 \%)$ & \\
\hline \multicolumn{6}{|c|}{ Table 3. Relationship of Age at Marriage and Parity with Cervi } & \\
\hline
\end{tabular}

Table 3 shows the relationship of age at marriage and parity with the cervical morbidity among the study subjects. As it is evident from the above table that most common per speculum finding found in all the age groups is cervical erosion or cervicitis, which was prevalent commonly between the age group of 18 - 25 years. Early age at Ist coitus has significant ( $p$ value $<0.001$ ) influence on cervical morbidity. Similarly, parity is also significantly ( $p$ value < 0.001 ) associated with type of cervical morbidity. As the parity increases, cervical morbidity is also on rise.

\begin{tabular}{|c|c|c|}
\hline Cytological Examination & No. & Percentage \\
\hline Normal & 458 & $91.6 \%$ \\
\hline ASCUS & 27 & $5.4 \%$ \\
\hline LSIL & 07 & $1.4 \%$ \\
\hline HSIL & 04 & $0.8 \%$ \\
\hline SCC & 04 & $0.8 \%$ \\
\hline Total & $\mathbf{5 0 0}$ & $\mathbf{1 0 0} \%$ \\
\hline
\end{tabular}

Table 4. Types of Cervical Dysplasia among Study Subjects

Table 4 shows the distribution of types of dysplasia. As it is evident from the above table that most common Pap smear lesion is ASCUS followed by LSIL.

\begin{tabular}{|c|c|c|c|c|c|c|}
\hline Age Group & Normal & ASCUS & LSIL & HSIL & SCC & Total \\
\hline$<18$ & 10 & 0 & 0 & 0 & 0 & 10 \\
\hline $18-25$ & 80 & 4 & 0 & 0 & 0 & 84 \\
\hline $26-30$ & 54 & 4 & 01 & 0 & 0 & 58 \\
\hline $31-35$ & 65 & 3 & 01 & 01 & 2 & 71 \\
\hline $36-40$ & 62 & 3 & 02 & 01 & 1 & 67 \\
\hline$>40$ & 194 & 13 & 03 & 02 & 1 & 210 \\
\hline Total & 465 & $\mathbf{2 7}$ & 07 & 04 & $\mathbf{0 4}$ & $\mathbf{5 0 0}$ \\
\hline \multicolumn{7}{|c|}{ Table 5. Distribution of Dysplasia as per Age } \\
\hline \multicolumn{7}{|c|}{} \\
\hline \multicolumn{7}{|c|}{}
\end{tabular}

Table 5 shows distribution of dysplasia as per age groups. Most common histopathological lesion found in all the age groups is ASCUS followed by LSIL and HSIL and SCC. The most common age group affected by ASCUS is $>40$ years of age study subjects.

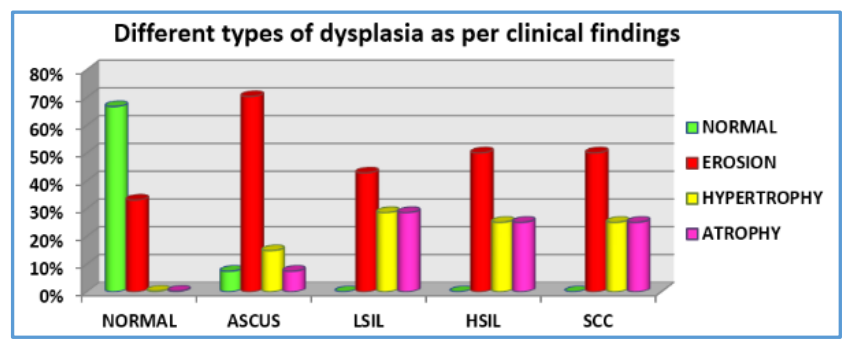

Figure 1. Showing Different Types of Dysplasia as per Clinical Findings

The Figure 1 is showing the different types of dysplasia detected by the Pap smear as per the clinical findings during the per speculum examination. Out of 458 normal cases, 151 were detected with cervical erosion or cervicitis. There were 42 abnormal smears, out of which most common was ASCUS (27).

\section{DISCUSSION}

The current study was carried out among 500 females attending Gynae OPD at a tertiary care centre. (PIMS) Most patients belonged to the age of 18 - 25 years. Majority of the participants got married at the age of $18-25$ years and the age of first coitus is maximum in the same age group, i.e. 18 25 years. The study shows that most common reproductive morbidity was discharge per vaginum $(30 \%)$ followed by pain lower abdomen (25.6\%). Similar findings were reported by Sharma P et al (2010) in a Community Based study on 
cervical cancer screening program among women of Delhi. The most common reproductive tract morbidity in their study was discharge per vaginum (28.5\%) followed by pain lower abdomen $(20.1 \%)$. Other complaints were post-coital bleeding, intermenstrual bleeding, something coming out of vagina, menorrhagia, dyspareunia, pruritus vulva, etc.(8) These could be attributed to poor personal hygiene. These observations were further supported by Desai M et al (2004) in Community Based Cancer Screening Program in Vadodara. ${ }^{(9)}$

The present study revealed that most common per speculum finding found in all the age groups was cervical erosion or cervicitis (41\%) and most common affected age group was 18 - 25 years. Age played a significant ( $p$ value $<0.001$ ) role in determining the type of cervical morbidity. Similarly, parity was also significantly ( $p$ value $<0.001$ ) associated with type of cervical morbidity. These findings were supported by Khamankar ST et al (2014) in a study conducted on risk factors for cervical neoplasia among rural women of Maharashtra, as in their study also factors like age and parity were significantly associated with cervical neoplasia. In their study, age and high parity were observed to be the risk factors for cervical neoplasia on Pap smear.(10) These findings were also consistent with study done by Gupta K et al (2013) on Cervical dysplasia in Western Uttar Pradesh, in which it was documented that prevalence of abnormalities in cervical smears were associated with age and parity.(11)

In the present study on Pap smear examination 42 (8.4\%) abnormal smears revealed 27 cases with ASCUS, 7 with LSIL, 4 with HSIL and 4 with Squamous Cell Carcinoma. These observations corroborate with findings of Bamanikar SA et al (2014) in a study on cervical pap smears in Pune, in which out of 30 abnormal smears most common were ASCUS type.(12) Similar trend was observed by Patel MM et al (2011) in a study on cervical pap smear, in which ASCUS was found to be the most common epithelial cell abnormality.(6)

\section{CONCLUSION}

The study clearly shows relatively high prevalence of epithelial abnormalities in cervical Pap smear with increasing age, parity, early age at first coitus in symptomatic women with clinical lesions on per speculum findings. Effective screening with Pap smear definitely helps in early detection of Precancerous lesions of cervix. Effective Frequent Pap smear screening programmes should be organised in India, even in the remotest rural areas to prevent the incidence of invasive cervical carcinoma.

\section{REFERENCES}

[1] Ferlay J, Shin HR, Forman D, et al. Estimates of worldwide burden of cancer in 2008: GLOBOCAN 2008. Int J Cancer 2010;127(12):2893-917.

[2] Kaarthigeyan K. Cervical cancer in India and HPV vaccination. Indian $\mathrm{J}$ Med Paediatr Oncol 2012;33(1):7-12.

[3] Nandakumar A. Ramnath T, Chaturvedi M. The magnitude of cancer cervix in India. Indian J Med Res 2009;130(3):219-21.

[4] Aswathy S, Quereshi MA, Kurian B, et al. Cervical cancer screening: current knowledge \& practice among women in rural population in Kerala, India. Indian J Med Res 2012;136(2):205-10.

[5] Shafi M. Premalignant and malignant disease of cervix. In: Edmonds DK. edr. Dewburst's textbook of obstetrics \& gynaecology. London Blackwell science 2008:614-24.

[6] Patel MM, Pandya AN, Modi J. Cervical PAP smear study and its utility in cancer screening, to specify the strategy for cervical cancer control. National Journal of Community Medicine 2011;2(1):49-51.

[7] Ruhi M, Sahi SC. Incidence of cervical intra-epithelial neoplasia in Faisalabad. Pak J Med Res 1997;32:164-5.

[8] Sharma P, Rahi M, Lal P. A community-based cervical cancer screening program among women of Delhi using camp approach. Indian J Community Med 2010;35(1):86-8.

[9] Desai M. An assessment of community based cancer screening program among Indian women using the anganwadi workers. J Obstet Gynecol Ind 2004;54(5):483-7.

[10] Khamankar ST, Belekar V, Bhagat VM, et al. Cervical cancer screening: risk factors for cervical neoplasia among rural women of Nanded, Maharashtra. Innovative Journal of Medical and Health Science 2014;4(1):312-6.

[11] Gupta K, Malik NP, Sharma VK, et al. Prevalence of cervical dysplasia in western Uttar Pradesh. J Cytol 2013;30(4):257-62.

[12] Bamanikar SA, Baravkar DS, Chandanwale SS, et al. Study of cervical pap smears in a tertiary hospital. Indian Medical Gazette 2014:250-4. 